\title{
Comparison of Aggressiveness Behavior of Chloride and Iodide Solutions on 304 and 304L Stainless Steel Alloys
}

\author{
Shaymaa Mahdi Salih'1, Ibtehal K. Shakir1, Abdulkareem M. A. Al-Sammarraie ${ }^{2 *}$ \\ ${ }^{1}$ Department of Chemical Engineering, College of Engineering, University of Baghdad, Baghdad, Iraq \\ ${ }^{2}$ Department of Chemistry, College of Science, University of Baghdad, Baghdad, Iraq \\ Email: *samuraee2000@hotmail.com
}

How to cite this paper: Salih, S.M., Shakir, I.K. and Al-Sammarraie, A.M.A. (2017) Comparison of Aggressiveness Behavior of Chloride and Iodide Solutions on 304 and 304L Stainless Steel Alloys. Materials Sciences and Applications, 8, 889-898. https://doi.org/10.4236/msa.2017.812065

Received: September 1, 2017

Accepted: November 13, 2017

Published: November 16, 2017

Copyright $\odot 2017$ by authors and Scientific Research Publishing Inc. This work is licensed under the Creative Commons Attribution International License (CC BY 4.0).

http://creativecommons.org/licenses/by/4.0/

\section{Open Access}

\begin{abstract}
The aggressive effect of chloride anion in comparison to iodide anion on the pitting corrosion attack of 304 and 304L stainless steel (SS) alloys was investigated by using the cyclic potentiodynamic polarization test at $0.6 \mathrm{M}$ Sodium Halide salts $(\mathrm{NaX})$ solution and different temperatures. The two alloys 304 and 304L SS suffered from severe pitting corrosion at room temperature up to $50^{\circ} \mathrm{C}$ in a chloride containing solution with the higher resistance observed for $304 \mathrm{~L}$ in comparison to the 304 while on pits were detected in iodide solution for both alloys. The pitting potentials of the two alloys in $0.6 \mathrm{M} \mathrm{NaCl}$ solution reduced with the increase of the temperature. Examination of the alloys' surfaces was conducted by using the scanning electron microscopes where it revealed that the occurrence of pitting attack seems like hemispherical or irregular pits with different sizes.
\end{abstract}

\section{Keywords}

Stainless Steel, Pitting Corrosion, Sodium Halide, Iodide

\section{Introduction}

The iron base alloy such as austenitic stainless steel (SS) with at least 16\% Chromium and 6\% Nickel referring to a series 300 (e.g., 304, 304L) has been widely used among other SS alloys in various industrial applications. As examples, architecture, food processing, transportation, kitchen equipment etc. However, these alloys suffer from pitting corrosion; a very localized attack (pits) when used in condition of high temperature with acidic solution including halide content and consequently leads to perforation of equipment, contamination and 
material loss [1] [2] [3] [4] [5].

Many studies have been devoted to understand the effect of temperature on the pitting corrosion potential $\mathrm{E}_{\mathrm{pit}}$ in a solution containing anion [6] [7] [8]. It was revealed that increasing the solutions temperature resulted in reducing protective properties of the passive film formed on these passivated metals as a consequence to increase the reactivity of the aggressive anions. This is in turn, resulted in shifting the $\mathrm{E}_{\text {pit }}$ towards more active potentials. However, there are a few research conducting the behavior of stainless steel in iodide solution combined with varying of working temperature [8]-[14], and their studies shows that the higher pitting potential $\mathrm{E}_{\mathrm{pit}}$ of stainless steel alloys found in the $\mathrm{I}^{-}$and $\mathrm{Br}^{-}$ion compared to lower value in $\mathrm{Cl}$ containing solution with the fact that the more strong adsorption ability seem to be less aggressive anion.

The aggressiveness of pitting corrosion caused by halide ion in terms of $\mathrm{E}_{\mathrm{pit}}$ was in the order of $\mathrm{Cl}^{-}>\mathrm{Br}^{-}>\mathrm{F}^{-}>\mathrm{I}^{-}$under different experimental condition and alloys composition was proved in several investigation [15] [16] [17] [18].

This study is aimed to investigate the effect of changing temperature $\left(20^{\circ} \mathrm{C}\right.$ $50^{\circ} \mathrm{C}$ ) on the susceptibility of the austenitic stainless steel (grade 304 and $304 \mathrm{~L}$ ) to the pitting corrosion in iodide containing solution in comparison to chloride anion.

\section{Experimental Procedure}

In this study, two types of austenitic stainless steel alloys (304 and 304L) were used. Their chemical compositions are given in Table 1. Testing specimens were cut from a plate with dimensions of $1.5,1.5,0.2 \mathrm{~cm}$ and an exposed working area of $1 \mathrm{~cm}^{2}$.

The working samples were initially subject to a grinding polishing using a series of abrasive papers starting from 300 grit up to 2000 grit finish until the surface appeared free from scratch. Then, the samples were rinsed by a distilled water, degreased in acetone, and rinsed again in an ethanol and finally dried by a heat gun in air and kept in the desiccators.

The tested solutions were $0.6 \mathrm{M} \mathrm{NaCl}(35.5 \mathrm{gm}$ in $1 \mathrm{~L})$ and $0.6 \mathrm{M} \mathrm{NaI}(89.93$ $\mathrm{gm}$ in $1 \mathrm{~L}$ ) have been prepared using laboratory grade reagents supplied from Sigma Aldrich by dissolving the required amount in distilled water prior to each experiment. The temperature of the tested solution was controlled by using cooling-heating circulating bath (Germany, HAAKE OOO-3959), the values of the pitting potential $\mathrm{E}_{\mathrm{pit}}$ as well as the repassivation potential $\mathrm{E}_{\text {rep }}$ were established using computerized potentiostat, (Mlab 200, Bank Elek. Int., Germany),

Table 1. The chemical compositions (wt. \%) of 304 and 304L SS specimens.

\begin{tabular}{ccccccccc}
\hline SS type & $\mathbf{C r}$ & $\mathrm{Ni}$ & $\mathrm{C}$ & $\mathrm{Mo}$ & $\mathbf{N}$ & $\mathrm{Mn}$ & $\mathrm{Si}$ & $\mathrm{Fe}$ \\
\hline 304 & 19.3 & 9.7 & 0.06 & 0.122 & 0.08 & 1.37 & 0.6 & bal \\
$304 \mathrm{~L}$ & 18.6 & 10.4 & 0.03 & 0.5 & 0.06 & 1.5 & 0.7 & bal \\
\hline
\end{tabular}


operated via software using a conventional three-electrode double glass wall corrosion cell with stainless steel alloys being the working electrode, saturated calomel electrode (SCE) as reference electrode and a platinum rod set as auxiliary electrode. The cyclic polarization curves were done by applying a potential range starting at $-400 \mathrm{mV}$ up to $1000 \mathrm{mV}$ with a positive sweep rate of $10 \mathrm{mV} / \mathrm{s}$ (SCE) then the potential shifted in the negative (opposite) direction until it contract the upward scan at a repassivation potential.

Finally, the morphology of the surfaces of 304 and 304L specimens were examined using Scanning Electron Microscope (SEM, Hitachi S-4500, Japan) after ending the cyclic polarization test.

\section{Results and Discussion}

\subsection{Effect of Temperature}

The effect of varying solutions $\mathrm{NaCl}$ and $\mathrm{NaI}$ temperature on grades 304 and 304L using cycling potentiodynamics polarization test were shown in Figures 1(a)-(d)) were Figure 1(a) and Figure 1(b) for 304 shows a positive hysteresis loop in $\mathrm{Cl}^{-}$containing solution indicating a metal susceptibility to pitting corrosion with the same behavior was observed for 304L SS in Figure 1(c) against a negative hysteresis loop with no sign to pitting corrosion in iodide containing solutions for 304 and 304L SS were shown in Figure 1(b) and Figure 1(d) respectively. The pitting corrosion characteristic represented as pitting potential $\mathrm{E}_{\mathrm{pit}}$ which represent the potential above were a pitting corrosion start while the re-passivation $E_{\text {rep }}$ potential bellow were no pitting occur or means the metal still passive and the intermediate potential region where no formation of new pit but allow the development of already exiting one can be distinguish from the cyclic polarization curves at different solutions temperature $\left(20^{\circ} \mathrm{C}-50^{\circ} \mathrm{C}\right)$ and halide salts for all studied alloys are shown in Figures 1(a)-(d).

It can observe from Figure 1 that an increase in the passive current density and a distinct decrease in values of $\mathrm{E}_{\mathrm{pit}}, \mathrm{E}_{\mathrm{rp}}$ and $\mathrm{E}_{\text {corr }}$ as the temperature increased from $20^{\circ} \mathrm{C}$ to $50^{\circ} \mathrm{C}$ in chloride solution, while it becomes active (toward the negative direction) in contrast to Iodide solution.

The chemisorption and diffusion of aggressive ion within the passive film increased at higher temperature leading to make a reduction in the protective properties of the passive film that may contribute in lowering the values of pitting potential. This means that a decrease in the resistance to pitting corrosion occurs as can be shown in Table 2 that the $\mathrm{E}_{\text {pit }}$ and $\mathrm{E}_{\text {rep }}$ are depending on the temperature for both alloys [6] [8] [15].

Reference [13] attributed the reduction in $\mathrm{E}_{\mathrm{pit}}$ value to the decreased in the level of dissolved oxygen due to increasing temperature, same result were got in this study as linear relationship and appeared in Figure 2.

The potential area without any risk to pitting corrosion $\mathrm{E}_{\mathrm{rep}}-\mathrm{E}_{\text {corr }}$ seems to be detrimental which indicates that 304L SS alloy experience a severe pitting corrosion in the chloride solution compared to 304 SS with no protection potential 


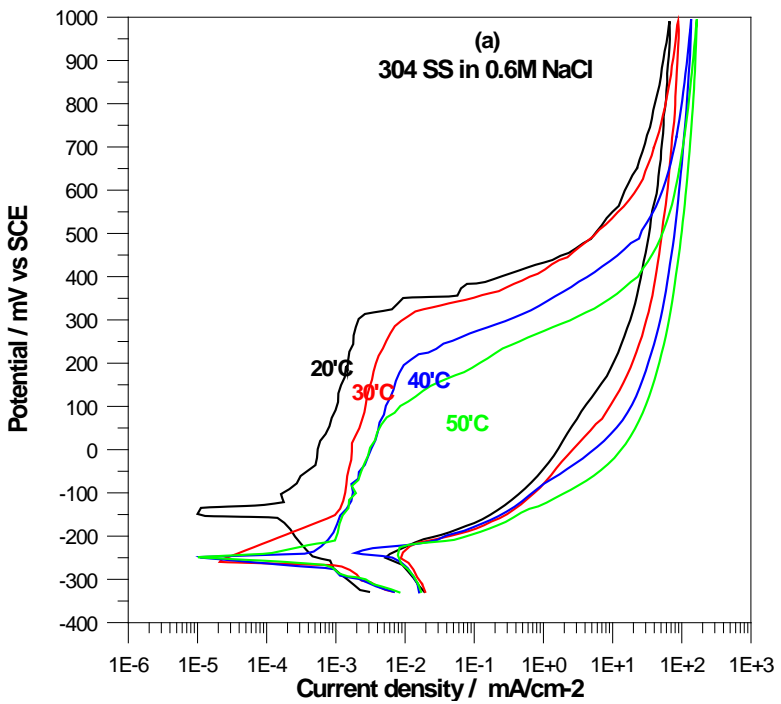

(a)

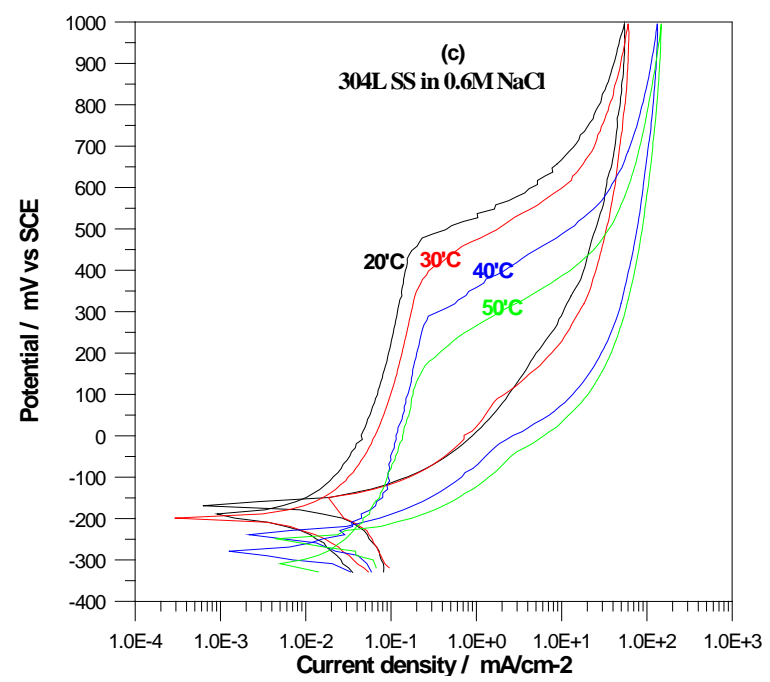

(c)

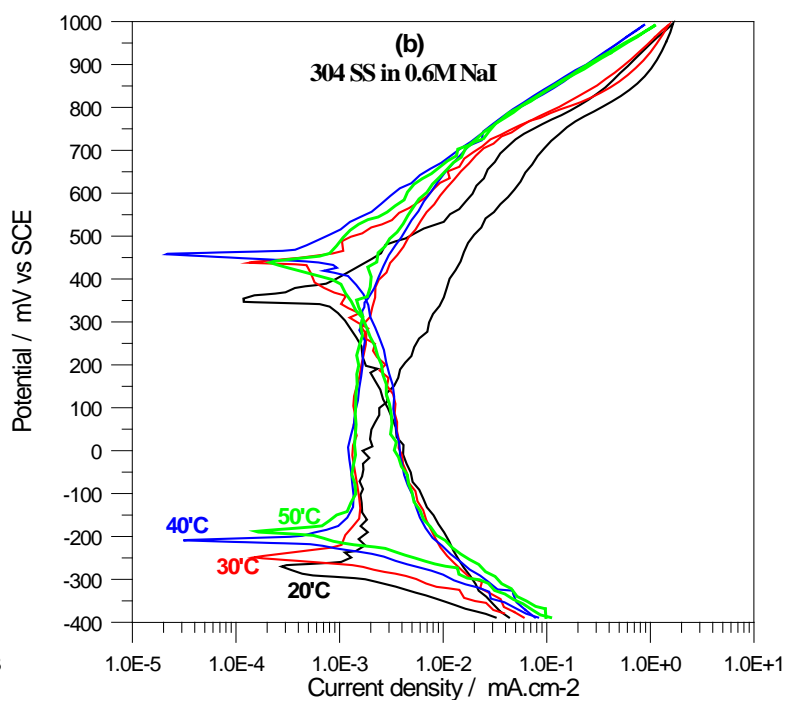

(b)

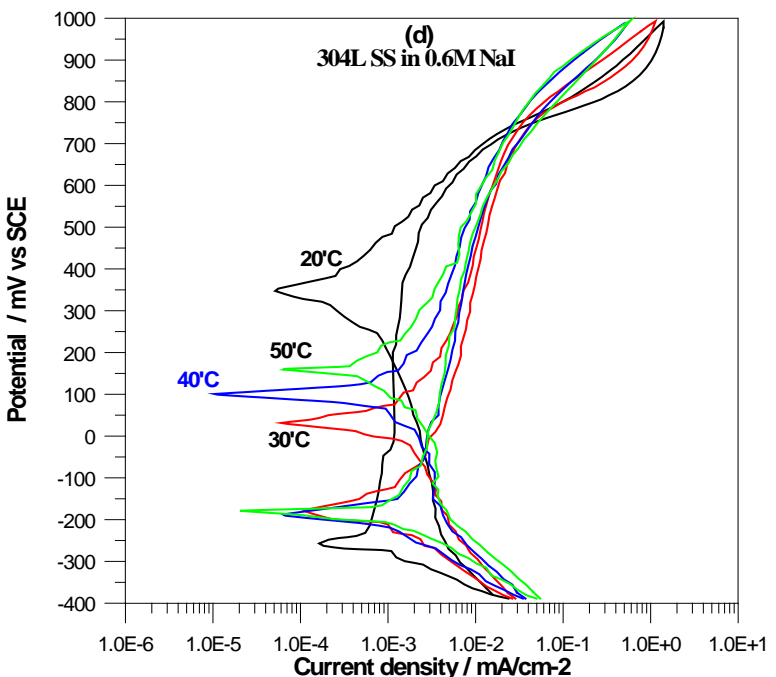

(d)

Figure 1. Cyclic polarization curves at different temperature for: (a) $304 \mathrm{SS}$ in $0.6 \mathrm{M} \mathrm{NaCl}$; (b) 304 SS in $0.6 \mathrm{M} \mathrm{NaI}$; (c) 304L SS in $0.6 \mathrm{M} \mathrm{NaCl}$; and (d) 304L SS in $0.6 \mathrm{M} \mathrm{NaI}$.

Table 2. The $\mathrm{E}_{\mathrm{pit}}$ and $\mathrm{E}_{\text {rep }}$ of 304 and $304 \mathrm{~L}$ in $0.6 \mathrm{M}$ chloride solution at different temperature.

\begin{tabular}{|c|c|c|c|c|c|}
\hline SS grades & Temp. ${ }^{\circ} \mathrm{C}$ & $\mathrm{E}_{\mathrm{rep}} \mathrm{mV}$ & $\mathrm{E}_{\mathrm{pit}} \mathrm{mV}$ & $\mathrm{E}_{\text {corr }} \mathrm{mV}$ & $\mathrm{E}_{\mathrm{pit}}-\mathrm{E}_{\text {corr }} \mathrm{mV}$ \\
\hline \multirow{4}{*}{ ర్ల } & 20 & No & 333.2 & -145 & 478.3 \\
\hline & 30 & No & 305.1 & -178.5 & 483.6 \\
\hline & 40 & No & 216.4 & -257.9 & 474.3 \\
\hline & 50 & No & 94.3 & -253.3 & 347.6 \\
\hline \multirow{5}{*}{ 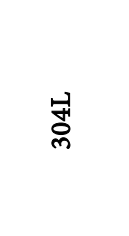 } & Temp. ${ }^{\circ} \mathrm{C}$ & $\mathrm{E}_{\text {rep }} \mathrm{mV}$ & $\mathrm{E}_{\mathrm{pit}} \mathrm{mV}$ & $\mathrm{E}_{\text {corr }} \mathrm{mV}$ & $\mathrm{E}_{\mathrm{pit}}-\mathrm{E}_{\text {corr }} \mathrm{mV}$ \\
\hline & 20 & -150.1 & 488.3 & -197 & 685.3 \\
\hline & 30 & -154.6 & 418.3 & -201.6 & 619.9 \\
\hline & 40 & -225.1 & 249.3 & -300 & 549.3 \\
\hline & 50 & -229.8 & 216.4 & -323.3 & 539.7 \\
\hline
\end{tabular}




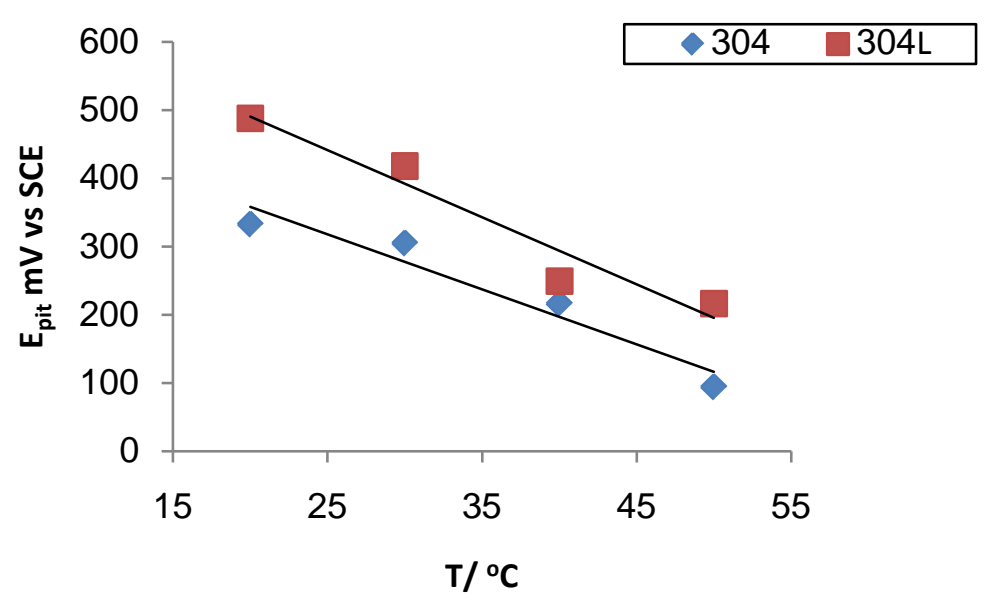

Figure 2. Temperature against $\mathrm{E}_{\mathrm{pit}}$ for 304 and $304 \mathrm{~L}$ in $0.6 \mathrm{M} \mathrm{NaCl}$.

area. Additionally, the potential area with the risk to pitting attack $\mathrm{E}_{\mathrm{pit}}-\mathrm{E}_{\text {corr }}$ and the $E_{p i t}-E_{\text {rep }}$ difference decreased with increasing of the temperature for both alloys as shown in Figure 3.

The potential difference between $\mathrm{E}_{\text {pit }}$ and $\mathrm{E}_{\text {corr }}$ decreased with increasing of the susceptibility to pitting corrosion as a result to the alloy composition relating to their calculated Pitting resistance equivalent number (PREN) values being 20.5 for $304 \mathrm{SS}$ and 21.05 for $304 \mathrm{~L}$ which proved a higher resistance of $304 \mathrm{~L}$ to pitting attack as compared to 304 alloy in the chloride solution.

\subsection{Halide Effect on Pitting Corrosion}

As mentioned above that the behavior of the two stainless steel alloys were investigated in sodium iodide and sodium chloride at different working conditions (temperatures) at $0.6 \mathrm{M} \mathrm{NaX}^{-}$. The cyclic polarization curve of 304 and $304 \mathrm{~L}$ in a solution containing chloride ion shows a clear signal of the pitting corrosion attack represented by the positive hysteresis loop shown in Figure 1. Figure 4 shows the comparison behavior of the halide ion $\left(\mathrm{Cl}^{-}\right.$and $\left.\mathrm{I}^{-}\right)$on stainless steel 304. A clear positive hysteresis loop were obtained for alloy in $\mathrm{NaCl}$ solution, while the behavior of iodide anion shows no sign to pitting corrosion with negative hysteresis loop. Thus, $\mathrm{Cl}^{-}$ions are aggressive enough to attack stainless steel and leads to a localized corrosion (e.g. pitting corrosion) due to small ion radius, which enable it to penetrate the oxide film under high electrical field present through the film as mentioned by researcher [16] [17] [19]. The electrical neutrality and hydrolysis of the corrosion product inside the pit was enhanced by $\mathrm{Cl}^{-}$ion migration cause $\mathrm{pH}$ dropped from 6 to 2 (acidification) facilitate the corrosion process as represented by the chemical Equation (1) [18] [20]:

$$
\mathrm{FeCl}_{2}+2 \mathrm{H}_{2} \mathrm{O} \rightarrow \mathrm{Fe}(\mathrm{OH})_{2}+2 \mathrm{HCl}
$$

A negative hysteresis loop obtained in iodide solution proved that these alloys in the exposed environmental conditions means do not pit due to increase passive film thickness at higher potential and becomes more protective and this will affect the dissolution rate [21]. 


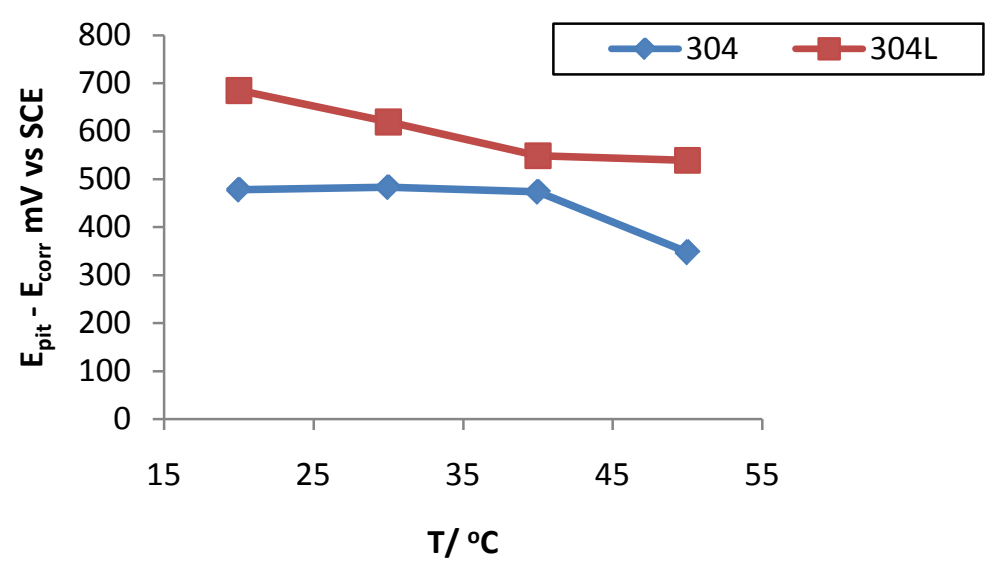

Figure 3. Potential difference between $\mathrm{E}_{\text {pit }}$ and $\mathrm{E}_{\text {corr }}$ vs. temperature in ${ }^{\circ} \mathrm{C}$.

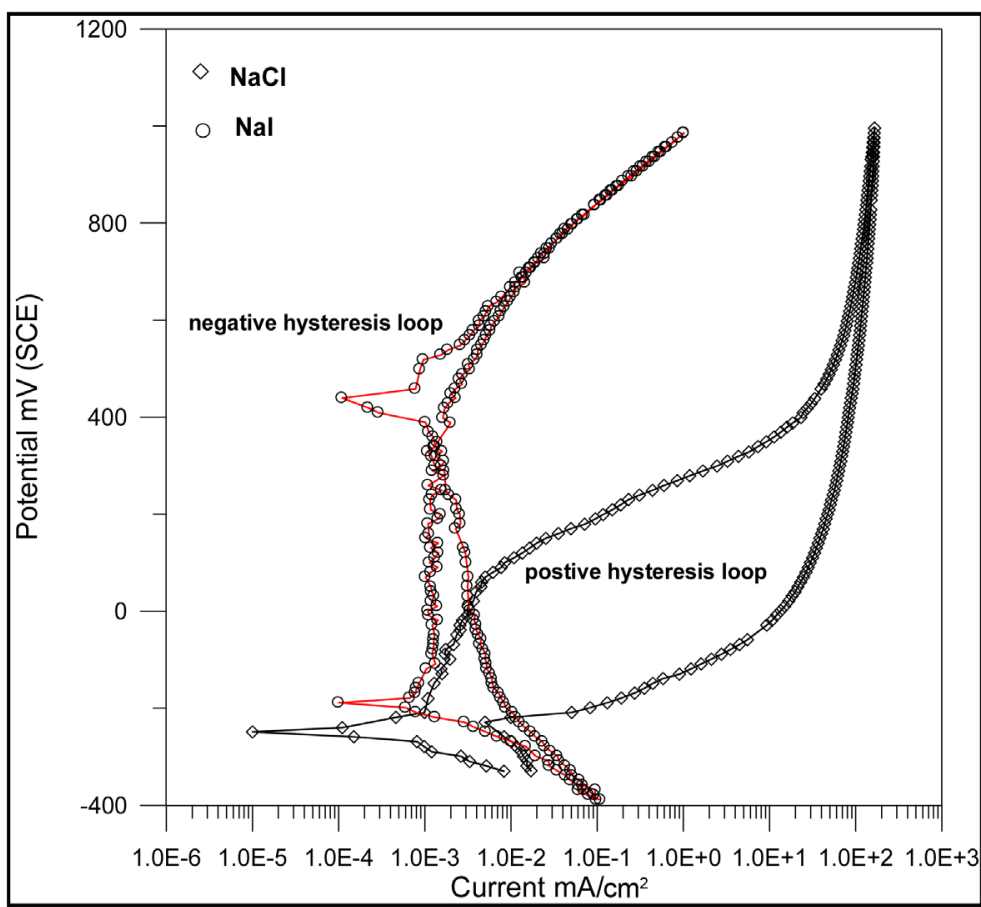

Figure 4. Corrosion behavior of $304 \mathrm{SS}$ in $\mathrm{NaCl}$ and $\mathrm{NaI}$ solution at $50^{\circ} \mathrm{C}$.

B.R. Tzaneva et al., [4], reported the same results in their studies and instructed the reason to the high reactivity of chloride ion with comparison to iodide ion. Decreasing the adsorption ability of the halide ion in the order $\mathrm{I}^{-}>$ $\mathrm{Br}^{-}>\mathrm{Cl}^{-}$with the resultant of lower electron injection to the oxide by iodide as well as the different stabilities of the halogen complex with metals.

\subsection{Morphology of Pitted Surfaces}

The surface of the pitted specimens, 304 and 304L SS in halide containing solution were examined by using OPM and SEM. A severe pitting attack can clearly observe from the images shown in Figure 5 for 304 and 304L alloys in chloride solution. The pits appeared to be open mouth hemispherical to irregular with a 


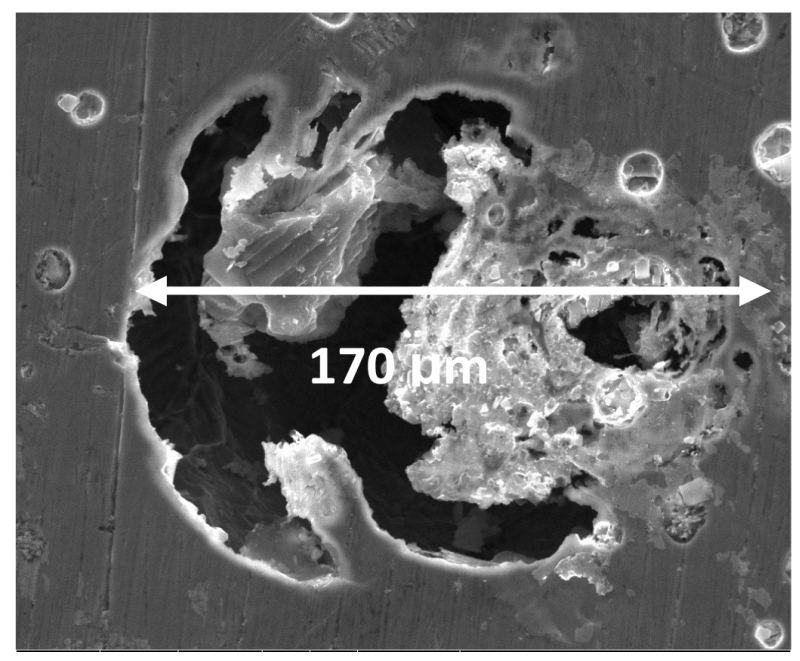

(a)

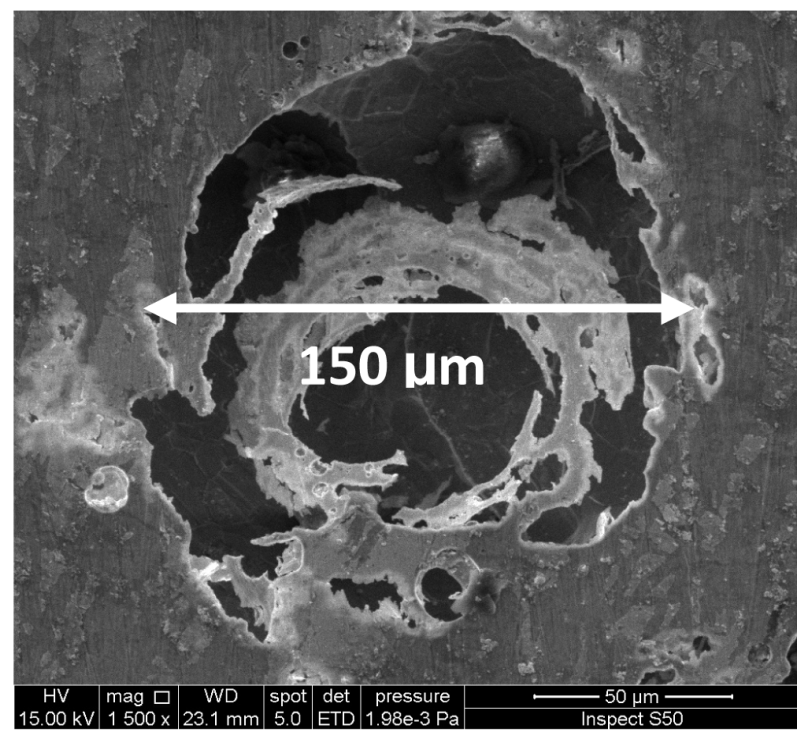

(b)

Figure 5. SEM images of the pits formed in $0.6 \mathrm{M} \mathrm{NaCl}$ solution at $50^{\circ} \mathrm{C}$ : (a) for $304 \mathrm{SS}$ and (b) for $304 \mathrm{~L}$ SS.

high density.

The tested samples in $0.6 \mathrm{M}$ iodide salt solution manifested no sign to pitting corrosion as these results coincide with that obtained from the cyclic polarization curve of the electrochemical test that shows a negative hysteresis loop in iodide medium and can be shown in Figure 6 (SEM images), with no pits can be noticeable for both alloys after the corrosion test, which agreed with that among halide types $\mathrm{F}^{-}$and $\mathrm{I}^{-}$did not exhibit a pitting corrosion tendency [22], which implies the formation of thickened passive film on the alloys surfaces preventing it from pitting attack.

\section{Conclusions}

Two stainless steel 304 and 304L alloys investigated against corrosion in this 


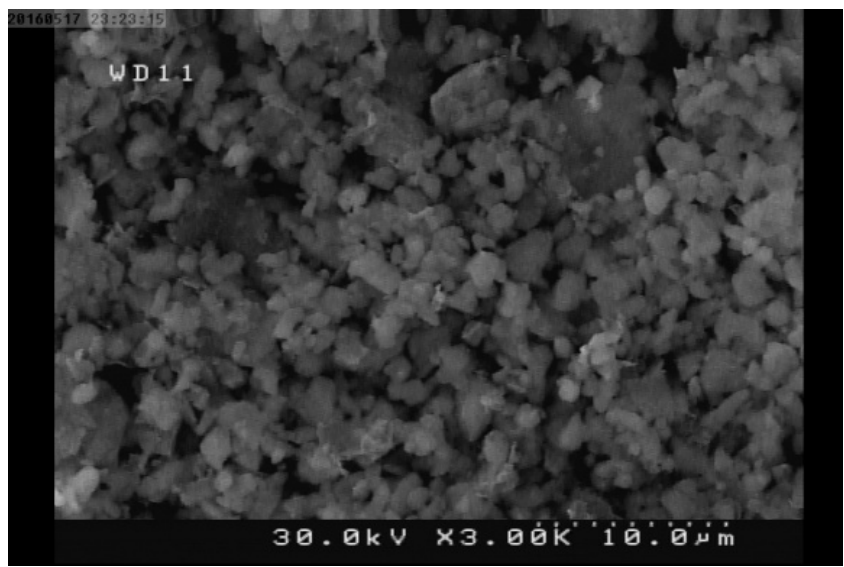

(a)

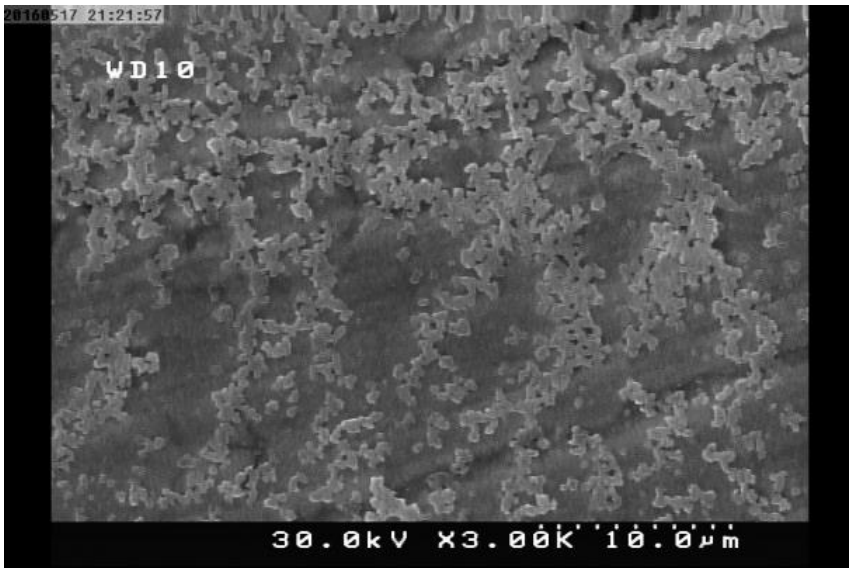

(b)

Figure 6. SEM images: (a) 304 and (b) 304L surface in NaI solution.

study, suffered a severe pitting corrosion at different working temperatures starting at $20^{\circ} \mathrm{C}$ up to $50^{\circ} \mathrm{C}$ in chloride containing solution, with higher resistance observed in $304 \mathrm{~L}$ against 304 due to the difference in the chemical alloys composition.

While no sign to pitting corrosion in iodide solution were observed for both alloys. The pitting potentials of the two alloys in $0.6 \mathrm{M} \mathrm{NaCl}$ solution reduced on increasing the temperature. Examination of the pitted surface evinces the occurring of pitting attack to the alloys under investigation in chloride containing solution with hemispherical to irregular pits with different sizes.

\section{References}

[1] Craig, B.D. and Anderson, D.S. (1995) Handbook of Corrosion Data. ASM International, USA. http://www.asminternational.org/

[2] Davis, J.R. (2001) Surface Engineering for Corrosion and Wear Resistance (No. 751) ASM International, USA.

[3] Roberge, P.R. (2007) Corrosion Inspection and Monitoring (Vol. 2). John Wiley \& Sons, Hoboken, NJ.

[4] Tzaneva, B.R., Fahcikov, L.B. and Raicheft, R.G. (2006) Effect of Halide Anions and 
Temperature on Initiation of Pitting in $\mathrm{Cr}-\mathrm{Mn}-\mathrm{N}$ and $\mathrm{Cr}-\mathrm{Ni}$ Steels. Corrosion Engineering Science and Technology, 41, 62-66.

[5] Schweitzer, P.A. (2006) Fundamentals of Metallic Corrosion: Atmospheric and Media Corrosion of Metals. 2nd edition, CRC Press Taylor and Francis Group, USA.

[6] Jeyaprabha, C., Sathiyanarayanan, S., Muralidharan, S. and Venkatachari, G. (2006) Corrosion Inhibition of Iron in $0.5 \mathrm{~mol} \mathrm{~L}-1 \mathrm{H}_{2} \mathrm{SO}_{4}$ by Halide Ions. Journal of the Brazilian Chemical Society, 17, 61-67. https://doi.org/10.1590/S0103-50532006000100009

[7] Tian, W., Du, N., Li, S., Chen, S. and Wu, Q. (2014) Metastable Pitting Corrosion of 304 Stainless Steel in 3.5\% NaCl Solution. Corrosion Science, 85, 372-379.

[8] Chou, Y.L., Wang, Y.C., Yeh, J.W. and Shih, H.C. (2010) Pitting Corrosion of the High-Entropy Alloy Co $1.5 \mathrm{CrFeNi} 1.5 \mathrm{Ti} 0.5$ Mo 0.1 in Chloride-Containing Sulphate Solutions. Corrosion Science, 52, 3481-3491.

[9] Azambuja, D.S., Martini, E. and Müller, I.L. (2003) Corrosion Behaviour of Iron and AISI 304 Stainless Steel in Tungstate Aqueous Solutions Containing Chloride. Journal of the Brazilian Chemical Society, 14, 570-576. https://doi.org/10.1590/S0103-50532003000400013

[10] Szklarska-Smialowska, Z. and ZS-Smialowska. (2005) Pitting and Crevice Corrosion. NACE International, Houston, TX, 88.

[11] Malik, A.U., Kutty, M., Siddiqi, N.A., Andijani, I.N. and Ahmad, S. (1990) Corrosion Studies on SS 316 L in Low pH High Chloride Product Water Medium. Saline Water Conversion Corp., Saudi Arabia.

[12] Galvele, J.R., Torresi, R.M. and Carranza, R.M. (1990) Passivity Breakdown, Its Relation to Pitting and Stress-Corrosion-Cracking Processes. Corrosion Science, 31, 563-571. https://doi.org/10.1016/0010-938X(90)90163-Y

[13] El Meguid, E.A. and El Latif, A.A. (2007) Critical Pitting Temperature for Type 254 SMO Stainless Steel in Chloride Solutions. Corrosion Science, 49, 263-275. https://doi.org/10.1016/j.corsci.2006.06.011

[14] Lee, S.U., Ahn, J.C., Kim, D.H., Hong, S.C. and Lee, K.S. (2006) Influence of Chloride and Bromide Anions on Localized Corrosion of 15\% Cr Ferritic Stainless Steel. Materials Science and Engineering: A, 434, 155-159. https://doi.org/10.1016/j.msea.2006.06.132

[15] Frankel, G.S., Stockert, L., Hunkeler, F. and Boehni, H. (1987) Metastable Pitting of Stainless Steel. Corrosion, 43, 429-436. https://doi.org/10.5006/1.3583880

[16] Kaneko, M. and Isaacs, H.S. (2000) Pitting of Stainless Steel in Bromide, Chloride and Bromide/Chloride Solutions. Corrosion Science, 42, 67-78. https://doi.org/10.1016/S0010-938X(99)00056-6

[17] Newman, R.C., Ajjawi, M.A.A., Ezuber, H. and Turgoose, S. (1988) An Experimental Confirmation of the Pitting Potential Model of Galvele. Corrosion Science, 28, 471-477. https://doi.org/10.1016/0010-938X(88)90069-8

[18] Tsutsumi, Y., Nishikata, A. and Tsuru, T. (2007) Pitting Corrosion Mechanism of Type 304 stainless Steel under a Droplet of Chloride Solutions. Corrosion Science, 49, 1394-1407. https://doi.org/10.1016/j.corsci.2006.08.016

[19] Ebrahimi, N., Momeni, M., Moayed, M.H. and Davoodi, A. (2011) Correlation between Critical Pitting Temperature and Degree of Sensitisation on Alloy 2205 Duplex Stainless Steel. Corrosion Science, 53, 637-644. https://doi.org/10.1016/j.corsci.2010.10.009

[20] Ahmad, Z. (2006) Principles of Corrosion Engineering and Corrosion Control. El- 
sevier Science \& Technology Books Publisher/BH.

[21] Kelly, R.G., Scully, J.R., Shoesmith, D. and Buchheit, R.G. (2002) Electrochemical Techniques in Corrosion Science and Engineering. CRC Press, Boca Raton. https://doi.org/10.1201/9780203909133

[22] Greene, N.D. and Fontana, M.G. (1959) A Critical Analysis of Pitting Corrosion. Corrosion, 15, 41-47. https://doi.org/10.5006/0010-9312-15.1.41 